\title{
PedAgogia do OPRIMIdo 50 ANOS DEPOIS: A ATUALIDADE DE PAULO FREIRE
}

\author{
João Paulo Guerreiro de Almeida \\ Instituto Federal de Educação, Ciência e Tecnologia do Ceará (IFCE), Limoeiro do Norte, \\ Ceará, Brasil \\ SeVERINO BEZERRA DA SILVA \\ Universidade Federal da Paraíba (UFPB), João Pessoa, Paraíba, Brasil
}

\begin{abstract}
REsumo: Este artigo pretende contribuir para o debate a respeito da atualidade e defesa da obra Pedagogia do Oprimido, que em 2018 completou 50 anos. Na ocasião, várias instituições de ensino se propuseram a comemorar o legado freiriano e reinventá-lo, incorporando análises sobre demandas atuais, a partir de eventos, livros e dossiês sobre a temática. Este trabalho reflete sobre o pensamento educacional de Paulo Freire, apontando as várias temáticas abordadas nas fontes consultadas, com foco nos desafios da educação brasileira frente ao Golpe de 2016 e ao avanço do movimento "Escola Sem Partido".
\end{abstract}

Palavras-chave: Pedagogia do Oprimido. Paulo Freire. Educação Libertadora. Educação Brasileira.

\section{INTRODUÇÃO}

No presente artigo, rememora-se Paulo Freire (1921-1997), educador pernambucano mundialmente conhecido pelas suas inovadoras experiências com a educação popular e a alfabetização/conscientização de adultos, na década de 1960. Suas teorias questionavam o modelo vigente de educação e buscavam uma transformação social mediante a tomada de consciência dos sujeitos históricos e sua consequente práxis libertadora. Sua vasta obra, renovadora e crítica, marcada por reflexões acerca da educação, em sentido amplo e estrito, com foco nas relações de opressão na sociedade, impulsiona e dá sentido à visão de mundo e à prática de educadores, sociedade civil e movimentos sociais em diversos espaços, formais e não formais.

Em 1963, ocorreu uma experiência de alfabetização e conscientização de 300 trabalhadores na cidade de Angicos, Rio Grande do Norte, que foi um divisor de águas, tanto no paradigma educacional em voga, como nas formas de percepção e atuação dos sujeitos da/na sua realidade. Todavia, a ideia de impulsionar um Método de Alfabetização de Adultos que partisse da realidade dos sujeitos, problematizando-a e buscando a superação das mazelas sociais e das práticas de opressão ali vivenciadas, foi vista com estranheza pelos setores reacionários que circundavam e/ou acompanhavam essas experiências. Nesse contexto, emergiam a participação popular e as Reformas de Base de João Goulart, bem como os movimentos de educação popular no Território 
Nordestino, tentativas democráticas que foram depois rechaçadas com o Golpe CivilMilitar de 1964.

Paulo Freire, exilado a partir desse evento, desenvolveu suas atividades inicialmente no Chile, onde escreveu ${ }^{1}$ Educação como Prática da Liberdade (1967), Pedagogia do Oprimido (1968) e Extensão ou Comunicação? (1969). No retorno ao Brasil, escreveu Conscientização (1979), Pedagogia da Esperança (1992) e Pedagogia da Autonomia, sua última obra, publicada pouco antes de sua morte em 1997.

No ano de 2018, tendo em vista as comemorações em alusão aos 50 anos da obra Pedagogia do Oprimido, várias instituições organizaram livros, dossiês e eventos, a fim de revisitar o pensamento educacional e a pedagogia de Paulo Freire, buscando, como o próprio sugere, sua reinvenção à luz das demandas atuais.

Este trabalho tem como objetivo refletir sobre a atualidade do pensamento de Paulo Freire, especificamente na obra Pedagogia do Oprimido, considerando as diversas temáticas abordadas em sua produção intelectual e os desafios da educação brasileira frente ao Golpe de 2016, além do avanço do Movimento "Escola Sem Partido".

Trata-se de um estudo bibliográfico à luz de Freire (2019, 2019a, 2019b, 2016), Brandão (2008) e Scocuglia (2018). Ainda foram consultadas as bases do Google Scholar a fim de identificar as produções mais recentes sobre a obra Pedagogia do Oprimido e sobre Paulo Freire. Por fim, elaboramos uma síntese acerca das principais temáticas e áreas que dialogam com o pensamento freiriano.

Retomar as experiências de Freire na Educação Popular e na Alfabetização de Adultos, assim como sua produção intelectual, na perspectiva de reinventá-la, ou seja, trazer novas leituras e ressignificações no tempo presente, tornou-se tarefa imprescindível e relevante, sobretudo nestes tempos de tanta desumanização e narrativas negacionistas. Em tempos sombrios, em que se pede fim à suposta "Doutrinação Marxista" e "Basta de Paulo Freire", consideramos fundamental debater esses paradigmas que denunciam as injustiças sociais e convocam à sua superação. A tarefa de reflexão sobre este contexto atual vem sendo levada a cabo pelos Institutos Paulo Freire e Universidades, no Brasil e no mundo, e serão analisadas adiante.

\section{A PEDAGOGIA DO OPRIMIDO}

Scocuglia (2018), ao apresentar as inter-relações entre as obras Pedagogia do Oprimido (1968) e Pedagogia da Esperança (1992), nos permite reconhecer que Freire foi um sujeito inserido no momento sócio-histórico do seu tempo, logo seu pensamento educacional está diluído em diversas publicações que dialogam com os contextos por ele vivenciados. Assim, as obras anteriormente citadas são continuidade das várias reflexões expressas no livro Educação Como Prática da Liberdade (1967) e na sua tese intitulada: "Educação e Atualidade Brasileira" (1959), resultante do concurso para a cátedra de História e Filosofia da Educação, da Escola de Belas Artes da Universidade do Recife.

Neste sentido, como mencionado anteriormente, as experiências de Freire em torno da educação popular e da alfabetização de adultos, no Brasil e no exílio, foram 
ALMEIDA, J. P. G. de; SILVA, S. B. da.

fundamentais para sua reflexão enquanto educador, uma reflexão que também o motivava à ação. Paulo Freire pensou um Sistema de Educação Nacional, iniciado, num primeiro momento, com o método de alfabetização para, posteriormente, destinar-se aos demais níveis de ensino, como educação primária e secundária, culminando em uma Universidade Popular (BRANDÃO, 2008). Todavia, como já foi salientado, com o Golpe Civil-Militar de 1964 houve uma brusca interrupção dessa ideia.

Discutir a Pedagogia do Oprimido exige uma leitura atenta e um esforço didático para a sua contextualização, visto que se trata de reflexões sobre a prática freiriana em torno da educação popular e da educação de adultos, mediadas pelos diversos contextos sócio-históricos em que se inseriu. Beisegel (1982) atesta três momentos do pensamento freiriano, identificando o primeiro no contexto do nacionaldesenvolvimentismo, embalado num viés mais reformista por parte do autor, quando da defesa de sua tese em 1959, culminando com as experiências do método de alfabetização; o segundo voltado ao contexto de exílio e, por fim, no seu retorno ao Brasil, o terceiro momento. Embora entendamos como uma questão complexa, optamos, para fins de visualização, por fazer uma breve apresentação sobre o método de alfabetização de adultos e suas inter-relações com as categorias teóricas tratadas na obra Pedagogia do Oprimido.

Brandão (2008) salienta que o método de alfabetização de adultos inicia-se no Serviço de Extensão e Cultura da Universidade do Recife e, posteriormente, foi aplicado em Angicos/RN, culminando com a alfabetização de 300 trabalhadores e trabalhadoras (de um total de 380) em 40 horas. Partindo da perspectiva da educação como ato político, com reconhecimento da diversidade epistemológica da comunidade, a primeira fase do método era a pesquisa do universo vocabular, do qual seriam extraídos os principais vocábulos do lugar, com 15 (quinze) a 18 (dezoito) palavras geradoras, assim designadas porque desvelavam a realidade dos educandos, tinham riqueza semântica e contemplavam todos os fonemas da língua portuguesa. Uma vez selecionadas pela equipe de alfabetização e por um ou mais representantes das comunidades, as palavras geradoras seriam analisadas no decorrer do processo de alfabetização política, a partir de temas geradores, que problematizavam a realidade dos educandos nesta diversidade epistemológica.

Esta problematização - denominada por Freire como leitura de mundo -, articulada ao diálogo dos sujeitos com o seu meio e com eles próprios, mediatizados pelas situações existenciais, impulsionava à tomada de consciência de sua situação de opressão, culminando na organização para superá-la. Podemos afirmar, mesmo que com ressalvas frente ao contexto nacional-desenvolvimentista, que tais experiências, articuladas ao exílio, foram a materialização da Pedagogia do Oprimido, antes mesmo que Paulo Freire a sistematizasse. Em Pedagogia da Esperança, Freire sinaliza que o livro Pedagogia do Oprimido

[...] apareceu numa fase histórica cheia de intensa inquietação. Os movimentos sociais na Europa, nos Estados Unidos, na América Latina, em cada espaço-tempo com suas características próprias. A luta contra a discriminação sexual, racial, cultural, de classe, a luta em defesa do ambiente, os Verdes, na Europa. Os golpes de Estado com a nova face, na América Latina, e seus governos militares que 


\begin{abstract}
se alongaram da década anterior. Os golpes de Estado agora ideologicamente fundados, e todos eles ligados de uma ou de outra maneira ao carro-chefe do Norte, na busca de viabilizar o que lhe parecia dever ser o destino capitalista do continente. As guerrilhas na América Latina; as comunidades de base, os movimentos de libertação na África, a independência das ex-colônias portuguesas, a luta na Namibia, Amilcar Cabral, Julius Nyerere, sua liderança na África e sua repercussão fora da África. A China. Mao. A Revolução Cultural. A extensão viva do significado de maio de 1968. As lutas político-sindicais e pedagógico-sindicais, todas obviamente políticas, sobretudo na Itália. Guevara assassinado na década anterior e sua presença como símbolo não apenas para movimentos revolucionários latino-americanos, mas também para lideranças e ativistas progressistas do mundo todo. A guerra do Vietnã e a reação no interior dos Estados Unidos (FREIRE, 2019a, p. 133).
\end{abstract}

Como sujeito histórico inserido criticamente no seu tempo, Paulo Freire escreveu Pedagogia do Oprimido num clima de efervescência política e contrahegemonia, tal como o que animava as experiências de educação popular da década de 1960, no Nordeste brasileiro. Neste sentido, logo ao início de Pedagogia do Oprimido, o autor sinaliza seu lugar de classe, junto aos marginalizados, aos quais dedica seus escritos: "Aos esfarrapados do mundo e aos que neles se descobrem e, assim, descobrindo-se, com eles sofrem, mas, sobretudo, com eles lutam" (FREIRE, 2019, p. 5). Essa primeira frase da Pedagogia do Oprimido é representativa, pois nos convida ao reconhecimento e à superação das situações de opressão. Não obstante, convoca outros sujeitos, não esfarrapados/as, a unirem-se à luta dos primeiros, que é a luta pela libertação de todos e todas, tão oportuna e atual neste momento sócio-histórico em que ainda levantamos a bandeira contra as opressões de classe, etnia, gênero e sexualidade, expressas nas relações de ódio aos empobrecidos, aos/às camponeses/as, negros/as, mulheres cis ou transexuais e à comunidade LGBTQIA $+^{2}$, historicamente invisibilizados/as em suas demandas e direitos, silenciados em suas denúncias e roubados de sua humanidade. Esses esfarrapados serão diversas vezes lembrados no decorrer deste trabalho.

Com relação à estrutura da obra, compõe-se de quatro capítulos, os quais abordam as seguintes questões: 1) A justificativa da Pedagogia do Oprimido; 2) A concepção bancária da educação; 3) Dialogicidade e 4) A teoria da ação antidialógica.

É importante registrar que neste trabalho traçamos uma discussão voltada a algumas categorias que atravessam a Pedagogia do Oprimido e as demais obras freirianas, quais sejam: diálogo, conscientização, práxis e liberdade/libertação.

Segundo Antunes, Gadotti e Padilha (2018), a tese central da sua obra é a liberdade/libertação:

\footnotetext{
A liberdade é categoria central de sua concepção educativa desde suas primeiras obras. A libertação é o fim da educação. A finalidade da educação será libertar-se da realidade opressiva e da injustiça. A
} 
ALMEIDA, J. P. G. de; SILVA, S. B. da

educação visa à libertação, à transformação radical da realidade, para melhorá-la, para torná-la mais humana, para permitir que homens, mulheres e pessoas não binárias sejam reconhecidos como sujeitos da sua história e não como objetos (ANTUNES; GADOTTI; PADILHA, 2018, p. 519). 43), é aquela

Mas, afinal, o que é a Pedagogia do Oprimido? De acordo com Freire (2019, p.

[...] forjada com ele/a e não apenas para ele/a, enquanto pessoas ou povos, na luta incessante de recuperação de sua humanidade. Pedagogia que faça da opressão e de suas causas objeto da reflexão dos oprimidos, de que resultará o seu engajamento necessário na luta por sua libertação.

Nesta definição, podemos visualizar o método de alfabetização de adultos, que anteriormente citamos, como a materialização da Pedagogia do Oprimido. Nele o conteúdo programático advém da comunidade como lócus de diálogos críticos, justificado quando Freire anuncia que a Pedagogia do Oprimido não pode ser elaborada pelos opressores. O autor reconhece as contradições entre opressores-oprimidos/as, bem como anuncia a necessidade de sua superação, quando aponta que a existência do opressor está condicionada à existência do/a oprimido/a. Para isto, necessita-se da tomada de consciência de sua situação de opressão.

Esse é um caminho para a libertação, aqui entendida como conquista, não é uma doação, bem como não se trata da sobreposição oprimido-opressor ou a inversão dos polos, mas a superação da contradição opressores-oprimidos. Nesse caminho, é relevante mencionar que a libertação não pode se dar em termos puramente idealistas ou exclusivamente práticos. O autor destaca a necessidade de entregar-se a uma práxis libertadora, pois reconhecer-se oprimidos/as e o engajamento para a libertação são condições essenciais para a superar a contradição em que eles/as se percebem.

Nas palavras de Carvalho e Pio (2017, p. 431),

Paulo Freire apresenta uma pedagogia que tem como fonte geradora a desconstrução da "ordem" social injusta e opressora. Portanto, trata-se de uma proposta educativa forjada pela e na práxis vivida social e historicamente e que requer a inserção crítica das massas em sua realidade, em busca de sua transformação.

Destarte, vemos uma compreensão de ação e reflexão em permanente dialética. $\mathrm{O}$ (re)conhecimento de sua situação de opressão se dá no diálogo, que Freire entende não ser uma simples transmissão de palavras sobre qualquer assunto, já que as palavras são prenhes de significado. O sentido do diálogo é, portanto, denúncia da realidade que, consequentemente, produz ação e reflexão.

Essa ideia de uma educação dialógica é bastante explorada em Pedagogia do Oprimido. Tomando como exemplo, o método de alfabetização, vemos que na pesquisa do universo vocabular há diálogo: com o contexto dos educandos/as, com as suas trajetórias de vida, anseios, percepções sobre a realidade e desafios do cotidiano. Por 
isso, Freire (2019, p. 114) concebe o diálogo como "[...] parte da existência humana através das relações sociais, dos processos do trabalho, da reflexão sobre sua ação. Assim, homens e mulheres se fazem, enquanto seres reflexivos e atuantes na sociedade". E complementa:

\begin{abstract}
Para o educador-educando, dialógico, problematizador, o conteúdo programático da educação não é uma doação ou uma imposição um conjunto de informes a ser depositado nos educandos -, mas a devolução organizada, sistematizada e acrescentada ao povo daqueles elementos que este lhe entregou de forma desestruturada (FREIRE, 2019, p. 116).
\end{abstract}

A comunidade como lócus de processos educativos que despertam para a criticidade é refletida neste processo. A compreensão das relações de opressão e de poder, no universo onde os sujeitos convivem, é um caminho à conscientização, ou seja, ao desenvolvimento crítico da tomada de consciência, com o sujeito se colocando numa postura de autorreflexão e de reflexão sobre seu tempo e seu espaço (FREIRE, 2019b). Trata-se de uma consciência histórica e de uma inserção crítica na história; ela se encontra na utopia e, neste sentido, dialetiza os atos de denunciar a anunciar (FREIRE, 2016).

Denúncia e anúncio. O processo de alfabetização política é conscientização, que, por sua vez, é denúncia acompanhada de anúncio, inéditos viáveis, futuros possíveis, mediante a práxis dos sujeitos. Para Freire, a práxis pode ser entendida como reflexão e ação dos homens e mulheres sobre o mundo para transformá-lo. Sem ela, é impossível a superação da contradição opressor-oprimido. Brandão (2008, p. 94-95) apresenta a ideia de práxis como o "[...] o trabalho político consciente, solidário, acompanhado sem cessar de sua persistente reflexão, feita por seus agentes".

Neste sentido, compreende-se que a Pedagogia do Oprimido tem muita força nas palavras e no agir. Consiste numa epistemologia que enfoca aspectos teóricocientíficos, mas também humanizadores e subjetivos, que tocam a nossa essência humana. Não obstante, o autor anuncia o caráter ideológico que o professor progressista precisa manter para não se desviar do caminho da esperança. Desta forma, a educação, no sentido freiriano, é dialógica, consciente, intencionada, portanto, crítica, e visa à colaboração, união, organização e síntese cultural. Ao contrário da educação bancária, identificada como ação antidialógica, que se volta à conquista e à manipulação a partir da imersão das consciências, separando os sujeitos de sua organização coletiva para, assim, manter a opressão. Logo, na proposição de uma sociedade democrática, Paulo Freire também propõe que ocorra a democratização da escola (FREIRE, 2019a; FREIRE, 1996).

Remetendo ao contexto atual, vemos que, pretensiosamente, desde o Golpe Parlamentar-Institucional de 2016, reprime-se com muita veemência a rebeldia dos esfarrapados diante da retirada de seus direitos. Os desdobramentos desse fato demarcam um momento de ataque a sindicatos, a movimentos e coletivos sociais. Em suas propostas, encontra-se uma "Escola sem Partido", ou seja, sem discussão crítica, 
ALMEIDA, J. P. G. de; SILVA, S. B. da

problematização da realidade, conscientização, práxis e libertação. Uma escola que em nada se aproxima do ideário freiriano. Tal proposta será retomada ao final deste texto.

\title{
Pedagogia do OPRIMIDO - 50 ANOS DEPOIS
}

Passadas cinco décadas desde a publicação de Pedagogia do Oprimido, em 1968, o legado do patrono da educação brasileira (Lei no 12.612, de 13 de abril de 2012) ainda se sustenta e ganha ressonância. Segundo Scocuglia (2018, p. 577):

\begin{abstract}
Em 2018 o livro "Pedagogia do oprimido", de Paulo Freire, completa 50 anos. Traduzido e publicado em todo o mundo tem sucessivas edições na América Latina, América do Norte, Europa, Ásia e África. Terceira obra mais citada, segundo levantamento do Google Scholar, em trabalhos acadêmicos das ciências humanas, soma mais de 70.000 referências em trabalhos rastreados. Além disso, encontra-se entre os 100 livros mais solicitados em Universidades de língua inglesa e em um milhão de ementas de estudos universitários americanos, ingleses, australianos e neozelandeses, entre outros. No campo das Ciências da Educação é o segundo autor mais citado em todo o mundo e tem 20 das suas principais obras na relação das mais estudadas.
\end{abstract}

Na ocasião dos 50 anos da obra Pedagogia do Oprimido, pudemos presenciar a organização de eventos, livros e dossiês em alusão ao pensamento freiriano, os quais propuseram, como solicitado pelo autor, a reinvenção de sua obra. Esta tarefa tornou-se imprescindível para anunciar que a pedagogia libertadora vive e é levada adiante. Em nosso levantamento, elencamos nove eventos, três livros e cinco dossiês sobre a Pedagogia do Oprimido, apresentados a seguir.

Quadro 1 - Eventos que celebraram os 50 anos da Pedagogia do Oprimido

\begin{tabular}{|c|c|c|c|}
\hline TÍTULO & INSTITUIÇÃO & TEMÁTICAS ABORDADAS & ANO \\
\hline $\begin{array}{l}\text { Congresso } \\
\text { Internacional "50 } \\
\text { Anos depois da } \\
\text { Pedagogia do } \\
\text { Oprimido" }\end{array}$ & $\begin{array}{l}\text { Instituto Paulo Freire de } \\
\text { Portugal e Universidade do } \\
\text { Porto }\end{array}$ & $\begin{array}{l}\text { Atualidade da obra; Desafios da } \\
\text { pedagogia freiriana; Reencontro } \\
\text { com a pedagogia do oprimido; } \\
\text { Políticas e práticas; Educação em } \\
\text { direitos humanos. }\end{array}$ & 2018 \\
\hline $\begin{array}{l}\text { Círculo de } \\
\text { diálogo em } \\
\text { comemoração } \\
\text { aos } 50 \text { anos do } \\
\text { livro Pedagogia } \\
\text { do Oprimido }\end{array}$ & $\begin{array}{l}\text { Universidade Federal da } \\
\text { Paraíba }\end{array}$ & $\begin{array}{l}\text { Pedagogia do Oprimido } 50 \text { anos } \\
\text { depois; Paulo Freire nos } \\
\text { Movimentos Sociais; Paulo Freire na } \\
\text { Filosofia da Educação Brasileira; } \\
\text { Encontros com Paulo Freire e } \\
\text { Michael Foucault. }\end{array}$ & 2018 \\
\hline
\end{tabular}




\begin{tabular}{|c|c|c|c|}
\hline $\begin{array}{l}\text { I Seminário } \\
\text { Nacional de } \\
\text { Filosofia, } \\
\text { Educação e } \\
\text { Pragmatismo }\end{array}$ & $\begin{array}{l}\text { Universidade Federal do } \\
\text { Piauí (UFPI) }\end{array}$ & $\begin{array}{l}\text { Filosofia, História e Ensino de } \\
\text { Filosofia; Pragmatismo Clássico e } \\
\text { neopragmatismo; Educação e } \\
\text { Pragmatismo no Brasil e América } \\
\text { latina. }\end{array}$ & 2018 \\
\hline $\begin{array}{l}\text { Simpósio } \\
\text { Comemorativo } \\
\text { dos } 50 \text { anos de } \\
\text { "Pedagogia do } \\
\text { Oprimido" e } \\
\text { Inauguração do } \\
\text { Auditório Paulo } \\
\text { Freire }\end{array}$ & $\begin{array}{l}\text { Instituto Federal de } \\
\text { Educação, Ciência e } \\
\text { Tecnologia de São Paulo }\end{array}$ & Vida e obra de Paulo Freire. & 2018 \\
\hline $\begin{array}{l}50 \text { anos da } \\
\text { Pedagogia do } \\
\text { Oprimido, de } \\
\text { Paulo Freire }\end{array}$ & $\begin{array}{l}\text { Universidade Federal do } \\
\text { Paraná (UFPR), Movimento } \\
\text { dos Trabalhadores Rurais } \\
\text { Sem Terra (MST), Fórum } \\
\text { Paranaense de Educação } \\
\text { de Jovens e Adultos }\end{array}$ & 50 anos da Pedagogia do Oprimido. & 2018 \\
\hline Paulo Freire Vive & $\begin{array}{l}\text { Universidade Federal de } \\
\text { Mato Grosso }\end{array}$ & Obra Pedagogia do Oprimido. & 2018 \\
\hline $\begin{array}{l}\text { Comemoração } \\
\text { dos } 50 \text { anos da } \\
\text { Pedagogia do } \\
\text { Oprimido }\end{array}$ & $\begin{array}{l}\text { Centro de Estudos da } \\
\text { Saúde do Trabalhador e } \\
\text { Ecologia Humana - } \\
\text { FIOCRUZ }\end{array}$ & Educação popular em Saúde. & 2018 \\
\hline $\begin{array}{l}\text { III Legado } \\
\text { Freiriano }\end{array}$ & $\begin{array}{l}\text { Universidade Estadual do } \\
\text { Ceará - UECE }\end{array}$ & $\begin{array}{l}\text { Educação Popular e Educação de } \\
\text { jovens e adultos; O pensamento } \\
\text { freiriano na educação do campo, } \\
\text { nos movimentos sociais, na } \\
\text { Extensão universitária; Círculos de } \\
\text { cultura. }\end{array}$ & 2019 \\
\hline $\begin{array}{l}\text { I COLÓQUIO } \\
\text { FREIRIANO: } 50 \\
\text { anos da pedagog } \\
\text { ia do oprimido }\end{array}$ & $\begin{array}{l}\text { Universidade Federal do } \\
\text { Maranhão }\end{array}$ & $\begin{array}{l}\text { Vida e obra de Paulo Freire e sua } \\
\text { contribuição para o campo } \\
\text { educacional. }\end{array}$ & 2019 \\
\hline
\end{tabular}

Fonte: Elaborado pelos autores a partir da pesquisa no Google Scholar(2021).

Destacamos três livros lançados, em alusão à Pedagogia freiriana, quais sejam: 1) Reinventando Freire: a práxis do Instituto Paulo Freire, organizados por Moacir Gadotti e Martin Carnoy em 2018, que reúne o esforço do IPF em catalogar e socializar experiências que remontem à prática pedagógica inspirada em Freire, na perspectiva de sua reinvenção. 2) Paulo Freire em tempos de fake news, organizados por Paulo Roberto 
ALMEIDA, J. P. G. de; SILVA, S. B. da

Padilha e Janaína Abreu em 2019, um livro que denuncia o negacionismo e revisionismo na atualidade; 3) 50 olhares sobre os 50 anos da Pedagogia do Oprimido, de Paulo Roberto Padilha, publicado em 2019, que trata de relatos de experiência e reflexões sobre a atualidade de Freire.

A seguir, destacamos o Quadro 2, que reúne dossiês organizados por periódicos nacionais e internacionais, em alusão aos 50 anos da Pedagogia do Oprimido.

Quadro 2 - Dossiês em alusão aos 50 anos da Pedagogia do Oprimido

\begin{tabular}{|l|l|l|l|}
\hline \multicolumn{1}{|c|}{ PERIÓDICO } & \multicolumn{1}{|c|}{ DOSSIE } & \multicolumn{1}{c|}{ INSTITUIÇÃO } & \multicolumn{1}{c|}{ ANO } \\
\hline $\begin{array}{l}\text { Revista Educação, } \\
\text { Sociedade e Cultura }\end{array}$ & $\begin{array}{l}\text { Celebrando Paulo Freire: novos e } \\
\text { velhos desafios na educação }\end{array}$ & $\begin{array}{l}\text { Universidade do } \\
\text { Porto }\end{array}$ & 2018 \\
\hline $\begin{array}{l}\text { Revista Arte de } \\
\text { Educar }\end{array}$ & $\begin{array}{l}50 \text { anos da Pedagogia do Oprimido: } \\
\text { Movimentos de opressões } \\
\text { e emancipações contemporâneas na } \\
\text { América Latina e África }\end{array}$ & $\begin{array}{l}\text { Universidade do } \\
\text { Estado do Rio de } \\
\text { Janeiro }\end{array}$ & 2018 \\
\hline $\begin{array}{l}\text { Revista Educação } \\
\text { em Perspectiva }\end{array}$ & $\begin{array}{l}\text { Pedagogia do Oprimido: } 50 \text { anos de } \\
\text { resistência }\end{array}$ & $\begin{array}{l}\text { Universidade Federal } \\
\text { de Viçosa }\end{array}$ & 2018 \\
\hline $\begin{array}{l}\text { Revista E- } \\
\text { curriculum }\end{array}$ & $\begin{array}{l}50 \text { anos da Pedagogia do Oprimido: } \\
\text { Ler a realidade e construir a esperança }\end{array}$ & $\begin{array}{l}\text { Pontifícia } \\
\text { Universidade Católica } \\
\text { - São Paulo }\end{array}$ & 2018 \\
\hline $\begin{array}{l}\text { Revista Debates } \\
\text { Insubmissos }\end{array}$ & 50 anos da Pedagogia do Oprimido & $\begin{array}{l}\text { Universidade Federal } \\
\text { do Pernambuco }\end{array}$ & 2019 \\
\hline
\end{tabular}

Fonte: Elaborado pelos autores a partir da pesquisa no Google Scholar(2021).

A partir de breve análise, percebemos que as temáticas abordadas nos eventos, livros e dossiês tratam de: motivos para estudar Paulo Freire; a atualidade da pedagogia freiriana; a reinvenção da obra; bases teóricas de Freire; encontros entre a Pedagogia do Oprimido e a Pedagogia da Esperança; "Escola Sem Partido"; movimentos sociais, sobretudo o Movimento dos Trabalhadores Rurais Sem Terra - MST, feminismo; tecnologias da informação e comunicação - TICs; informática educativa; educação ambiental; prática pedagógica; currículo; educação em direitos humanos; extensão universitária; novos olhares sobre o oprimido, destacando os refugiados e juventudes periféricas como tal; educação popular; educação popular em saúde; educação de jovens e adultos; educação integral; hip hop como prática da liberdade; educação cidadã; arte-educação e teatro do oprimido.

As produções recentes apresentam: a atualidade da obra; novos olhares sobre o/a oprimido/a; áreas que dialogam com o pensamento freiriano, a exemplo da educação, artes, saúde, música, comunicação, informática; reflexões sobre a Pedagogia do Oprimido no ambiente escolar e em outros espaços formativos; os desafios e as oposições a uma Pedagogia do Oprimido na atualidade. As categorias oprimido, diálogo, conscientização e libertação são diversas vezes retomadas nas produções atuais e reinventadas à luz do atual contexto. Não obstante, com temáticas diversas e pluralidade regional nas investigações, os trabalhos publicados nos referidos dossiês ratificam a constatação de Brandão (2008, p. 92) sobre as iniciativas de educação popular com base na pedagogia freiriana: 
[...] surgem e ressurgem ao longo do tempo por toda a parte: movimentos sociais do campo e da cidade, de trabalhadores, sindicatos, oposições sindicais, associações populares, assembleias do povo, grupos de bairro, de vizinhança, de comunidade, de saúde, dentre outros.

Junto à atualidade da obra de Freire, mostram-se também atuais e ressignificadas as demandas em torno de uma pedagogia libertadora. No entanto, tal como na década de 1960, há resistências a esse paradigma. Em seu bojo, encontram-se as relações de classe e uma educação pouco compromissada com a transformação social.

\section{POR UMA ESCOLA SEM MORDAÇA}

Tornam-se evidentes os enfrentamentos entre os que defendem uma educação voltada à contestação do status quo e os que propõem uma "Escola Sem Partido" (ESP), "sem ideologia", como dizem, quando, na verdade, a narrativa (falsa) de neutralidade já é bastante ideológica - no sentido mais inconsistente da ideologia, como falseamento da realidade. Essas reações à educação libertadora também acompanharam as manifestações que pediam a renúncia e/ou o impeachment da presidenta Dilma Roussef, logo após o início do seu segundo mandato em 2015.

De acordo com Hermida e Lira (2021), o ESP ${ }^{3}$ começa a ser organizado por Miguel Nagib em 2004 e, posteriormente, sobretudo desde 2016, foram propostos projetos de lei, em sua maioria, não aprovados, mas que permanecem como bandeira dos segmentos ultraconservadores da direita brasileira, representados tanto na política partidária como nas religiões extremistas, cujas ações se materializam na perseguição a professores da educação básica e do ensino superior, no cerceamento de ideias e em prol de uma educação sem pensamento crítico. A ESP subentende uma escola com mordaça; contra os esfarrapados; uma escola sem diálogo, sem indagação crítica e conscientização, logo, que não caminha para a autonomia do sujeito e para a libertação. Esse é um dos vários motivos pelos quais esses ultraconservadores pediram e continuam a pedir "basta de Paulo Freire". Conforme Gadotti (2016 apud Vasconcelos e Brandão, 2018, p. 306),

A expressão "Escola sem partido" e "Escola de partido único" são sinônimos. Trata-se de uma escola sem pluralidade, sem liberdade, sem diversidade, sem inclusão, sem democracia, uma escola que segrega, que discrimina, que reprime. Além disso, o movimento da Escola Sem Partido é um movimento a favor da privatização da educação. Primeiro desqualifica a escola pública para, depois, propor "recuperar" essa escola por meio da gestão privada ou dos critérios privados de institutos e fundações empresariais. A Escola Sem Partido é apenas mais uma tentativa de destruir a Escola Democrática, a Escola Cidadã, uma conquista da Constituição de 1988 e da Lei de Diretrizes e Bases da Educação Nacional de 1996. 
De tal modo, os 50 anos da Pedagogia do Oprimido marcam não apenas a importância histórica da obra, mas retomam os desafios nela expressos. Tal como na década de 1960, quando a pedagogia freiriana foi considerada subversiva, há uma tentativa de articular educação e economia, com vistas a fortalecer a narrativa do projeto de desenvolvimentismo. Nos anos que se sucederam Pós-Golpe de 1964, a Teoria do Capital Humano ${ }^{4}$ impactou diretamente na política de alfabetização de adultos, como forma de capacitá-los e inseri-los no mercado de trabalho, com clara valorização dos que participam da lógica de sociedade proposta pelo governo militar, nos aspectos políticos, ideológicos e econômicos. A legislação, a exemplo da lei 5692/1971 - Reforma do Ensino de $1^{\circ}$ e $2^{\circ}$ grau, que dentre outras providências, estabeleceu um currículo voltado à profissionalização, também sofre influências desse contexto. De acordo com Saviani (2005, p. 8),

[...] a subordinação da educação ao desenvolvimento econômico significava torná-la funcional ao sistema capitalista, isto é, colocá-la a serviço dos interesses da classe dominante: ao qualificar a força de trabalho, o processo educativo concorria para o incremento da produção da mais-valia, reforçando, em conseqüência, as relações de exploração.

Essa perspectiva vem sendo retomada a partir das reformas implementadas Pós-Golpe Parlamentar de 2016, que destituiu a presidenta Dilma Roussef. A ótica neoliberal que molda as políticas e reformas educacionais se expressa na Reforma do Ensino Médio (Lei no 13.415/2017) e na Base Nacional Comum Curricular - BNCC. A primeira institui uma formação profissional como integrante do currículo de nível médio e suplanta a formação humanística; já a BNCC pressupõe uma base curricular, de caráter duvidoso, no que concerne ao lugar das ciências humanas no currículo.

Importa mencionar ainda a Reforma Trabalhista, instituída pela Lei n 13.467, de 13 de julho de 2017, que retira direitos conquistados pela classe trabalhadora e precariza as relações de trabalho terceirizado. Acrescenta-se ao pacote, a tentativa de uma Reforma da Previdência, culminando na tríade perversa de formação para o trabalho explorado e precarizado, sem direito a uma duvidosa aposentadoria.

Outras questões atuais, como os projetos de privatização de universidades (FUTURE-SE ${ }^{5}$ ), intervenções nas Instituições de Ensino Superior (IES) e cortes de bolsas de iniciação científica e pós-graduação, especialmente nas ciências humanas, denunciam também uma realidade de negacionismo e cerceamento do pensar crítico.

A educação libertadora não cabe nesse projeto de sociedade, uma vez que em seu cerne está o (re)conhecimento da situação de opressão, com vistas à organização para superá-la. Nessa lógica perversa, cabe o movimento de "Escola Sem Partido", que promove a imersão das consciências na roda mercadológica e contraria a concepção libertadora da educação. Logo, impõe-se a nós a necessidade resistir e defender o legado de Paulo Freire. Trata-se de um momento em que o diálogo ganha lugar privilegiado e mostra-se deveras necessário a fim de combater a desumanização e o discurso negacionista. Mostra-se imprescindível retornar às bases, reinventar as experiências de educação dentro e fora do ambiente escolar. Desfazer certos "mitos": este pode ser um bom tema gerador! 
Este artigo vem sendo construído num diálogo intersubjetivo, carregado das atuais experiências de resistência ao neofascismo, refletidas à luz da pedagogia freiriana. Os esfarrapados, referenciados ao longo deste texto, vêm se levantando contra a opressão. O assassinato cruel de George Floyd, em abordagem policial, em Minneapolis/EUA, em 25 de maio de 2020, escancarou o racismo estrutural ao mesmo tempo em que impulsionou o movimento Black Lives Matter (Vidas Negras Importam), que vem ganhando ressonância e promovendo reações. Protestos em Minneapolis anunciam o levantar de vozes contra a opressão, ao qual a elite, representada pelo Estado burguês e conservador, reage com mais opressão. Freire já o anuncia em Pedagogia do Oprimido.

Para as elites dominadoras, esta rebeldia, que é ameaça a elas, tem o seu remédio em mais dominação - na repressão feita em nome, inclusive, da liberdade e no estabelecimento da ordem e da paz social. Paz social que, no fundo, não é outra senão a paz privada dos dominadores (FREIRE, 2019, p. 92).

Caminhando para as considerações finais, cabe-nos mencionar alguns esfarrapados: o menino Miguel, do Recife, vítima de uma elite que, mesmo diante de uma pandemia, não abre mão de seu lugar de privilegiada. Miguel acompanhava a mãe em seu serviço. Empregada doméstica, ela levou os cachorros dos patrões para o passeio matinal e deixou o filho aos cuidados da patroa que negligente permitiu que a criança pegasse sozinha o elevador. Nesse curto tempo, Miguel caiu do nono andar do prédio e não resistiu. Essa tragédia denuncia a desigualdade social: enquanto uns detêm o privilégio do isolamento social, há quem não possua o mesmo direito e arrisca-se em busca de sua subsistência. Outros sujeitos marginalizados são lembrados neste escrito: João Pedro Matos (14 anos), Ágatha Félix (8 anos), Evaldo Rosa dos Santos, morto com 80 tiros, vítimas do racismo e da violência policial no Rio de Janeiro, no ano de 2019. Dandara, mulher transexual apedrejada e morta no Ceará, no ano de 2017.

A Pedagogia do Oprimido problematiza as realidades desses e de tantos outros e propõe que se rompa com esta situação de opressão, ainda bastante presente na realidade brasileira, buscando, sobretudo, a transformação social. Lembrá-los neste momento implica em denúncia, que como tal exige anúncio/intervenção, como Freire propôs.

\section{CONSIDERAÇÕES FINAIS}

Este diálogo com as produções que tivemos acesso em alusão aos 50 anos da Pedagogia do Oprimido, em consonância com uma breve análise sobre o contexto atual, possibilitou-nos refletir sobre a urgência e a necessidade de uma educação crítica e comprometida com a libertação dos oprimidos. Todavia, merecem aprofundamento em estudos posteriores os impactos dos movimentos conservadores no chão de sala e no currículo escolar, bem como os processos de resistência a estes ataques e a reinvenção da pedagogia libertadora nas práticas educativas de professores de diversos níveis e 
ALMEIDA, J. P. G. de; SILVA, S. B. da.

modalidades de ensino, nos movimentos sociais, na educação popular e também na educação pública. Esta será uma tarefa para aqueles que se empenharão na construção dos eventos em alusão ao Centenário de Paulo Freire em 2021.

Nestes tempos em que os ultraconservadores se ocupam em pedir um "Basta de Paulo Freire", a pedagogia libertadora ressurge com mais força e resistência na prática social de segmentos oprimidos e de estudiosos comprometidos com mudanças estruturais no nosso país, que politizam, sonorizam e narram suas pautas. Assim, as possibilidades de esperançar criticamente, na perspectiva da transformação social, também podem ganhar mais tônus.

Artigo recebido em: 01/04/2021

Aprovado para publicação em: 29/06/2021

\section{PEDAGOGY OF THE OPPRESSED 50 YEARS LATER: THE ACTUALITY OF PAULO FREIRE}

ABSTRACT: This article intends to contribute to the debate about the actuality and defense of the work Pedagogy of the Oppressed, which in 2018 completed 50 years. On the occasion, several educational institutions proposed to celebrate Freire's legacy and reinvent it, incorporating analyses on current demands, from events, books and dossiers on the theme. This article reflects on Paulo Freire's educational thought, pointing out the various themes addressed in the sources consulted, focusing on the challenges of Brazilian education in the face of the 2016 coup and the advance of the "Escola Sem Partido" movement.

KEYWORDS: Pedagogy of the Oppressed. Paulo Freire. Liberating Education. Brazilian Education.

\section{PEDAGOGÍA DE LOS OPRIMIDOS 50 AÑOS DESPUÉS: ACTUALIDADE DE PAULO FREIRE}

RESUMEN: Este artículo intenta contribuir al debate sobre la relevancia y defensa de la obra Pedagogia de los Oprimidos, que en 2018 cumplió 50 años. En ese momento, varias instituciones educativas se propusieron conmemorar el legado de Freire y reinventarlo, incorporando análisis de las demandas actuales, desde eventos, libros y dossiers sobre el tema. Este trabajo reflexiona sobre el pensamiento educativo de Paulo Freire, señalando los diversos temas abordados en las fuentes consultadas, enfocándose en los desafíos de la educación brasileña frente al golpe de 2016 y el avance del movimiento Escuela Sin Partido.

PalabRAS CLAVE: Pedagogía del Oprimido. Paulo Freire. Educación Liberadora. Educación Brasileña. 


\section{NOTAS}

1 - Destacamos que as referências ora mencionadas representam um recorte das mais de 40 obras de Paulo Freire.

2 - LGBTQIA+: Lésbicas, Gays, Bissexuais e Transexuais, Queer, Intersexo, Assexual. Utiliza-se o + na intenção de incluir outros grupos e suas variações de sexualidade e de gênero, a exemplo dos pansexuais, que se atraem por outras pessoas, independente do gênero.

3 - Espinosa e Queiroz (2017, p. 51) destacam que em 11 estados brasileiros tramitaram projetos do ESP. Um destes estados foi Alagoas (AL), que teve o Projeto aprovado e convertido na Lei $n^{\circ}$ 7800/2016, todavia declarada inconstitucional pelo STF. Além dos projetos tramitados em âmbito estadual, em diversas Câmaras Municipais tramitaram projetos do ESP. Destacamos ainda alguns municípios elencados pelos autores anteriormente mencionados: Curitiba (PR), Joinville (SC), Rio de Janeiro (RJ), Santa Cruz do Monte Castelo (PR), Picuí (PB), São Paulo (SP), Toledo (PR), Vitória da Conquista (BA), Cachoeiro de Itapemirim (ES) e Foz do Iguaçu (PR).

4 - Na obra Capital Humano: Investimentos em Educação e Pesquisa (1971), Theodore Schultz desenvolve a Teoria do Capital Humano, que articula educação e desenvolvimento econômico.

5 - A discussão sobre o "Future-se" passa a ocorrer no primeiro ano do mandato de Jair Messias Bolsonaro, em 2019, na ocasião das manifestações contra o contingenciamento de recursos da educação superior, bem como diante do cancelamento de bolsas de pós-graduação: em 2019 foram canceladas cerca de 18 mil bolsas de pesquisa e pós-graduação ( 9.842 do CNPq e 8.050 da Capes) (SGUISSARDI, 2020, p. 156). No campo do ensino superior, o "Future-se" é uma das iniciativas que, dentre outras decisões, versa sobre a autonomia universitária e sobre o financiamento. Em seu artigo $1^{\circ}$ destaca que se propõe a: "I - incentivar fontes privadas adicionais de financiamento para projetos e programas de interesse de universidades e institutos federais" (Brasil, 2020), e trata de forma nebulosa como serão geridos e patenteados os resultados. Se a princípio parece animador, na perspectiva de obter mais recursos às IES, isto pode desresponsabilizar o Estado quanto ao financiamento do ensino superior, sobretudo na pesquisa. Logo se desvela a farsa e torna-se algo preocupante, pois a iniciativa privada tem interesses que transformam a ciência em mercadoria; este pode ser um caminho à privatização de IES (LEHER, 2020).

REFERÊNCIAS

ANTUNES, A. B.; GADOTTI, M.; PADILHA, P. B. Três categorias que marcaram a Pedagogia do Oprimido. Educação em perspectiva, Brasil, v. 9, n. 3, set./dez. 2018.

BEISIEGEL, C. R. Política e educação popular; a teoria e a prática de Paulo Freire no Brasil. São Paulo: Ática, 1982.

BRANDÃO, C. R. O que é método Paulo Freire. São Paulo: Brasiliense, 2006.

BRASIL. Diário Oficial da União. Publicado em: 03/01/2020. Edição 2, Seção 1, Página 1. Órgão: Presidência da República/Casa Civil. Disponível em: <http://www.in.gov.br/en/web/dou/-/despacho-236403674 >. Acesso em: 29 jun. 2021. 
ALMEIDA, J. P. G. de; SILVA, S. B. da.

BRASIL. Lei n 13.415, de 16 de Fevereiro de 2017. Altera as Leis $\mathrm{n}$ ० 9.394, de 20 de dezembro de 1996, que estabelece as diretrizes e bases da educação nacional, e 11.494, de 20 de junho 2007, e institui a Política de Fomento à Implementação de Escolas de Ensino Médio em Tempo Integral. Brasília: 2017.

BRASIL. Lei № 13.467, de 13 de Julho de 2017. Altera a Consolidação das Leis do Trabalho (CLT), aprovada pelo Decreto-Lei $\mathrm{n}^{\circ} 5.452$, de $1^{\circ}$ de maio de 1943 , e as Leis $\mathrm{n}{ }^{\circ}$ 6.019, de 3 de janeiro de 1974, 8.036, de 11 de maio de 1990, e 8.212, de 24 de julho de 1991, a fim de adequar a legislação às novas relações de trabalho. Brasília: 2017.

BRASIL. Lei n 12.612, de 13 de abril de 2012. Declara o educador Paulo Freire Patrono da Educação Brasileira. Brasília, 2012. Disponível em: $<$ http://www.planalto.gov.br/ccivil_03/_ato20112014/2012/lei/l12612.htm\#: :text=LEI\%20N\%C2\%BA\%2012.612\%2C\%20DE\%2013,eu\% 20sanciono $\% 20 \mathrm{a} \% 20$ seguinte $\% 20$ Lei $\% 3 A \&$ text $=1 \%$ C2\%BA\%200\%20educador\%20Paul o\%20Freire\%20\%C3\%A9\%20declarado\%20Patrono\%20da\%20Educa\%C3\%A7\%C3\%A3o \%20Brasileira >. Acesso em: 15 mar. 2021.

BRASIL. Lei 5.692, 11 ago. 1971. Fixa as Diretrizes e Bases para o ensino de $1^{\circ}$ e $2^{\circ}$ graus, e dá outras providências. Brasília, 1971. Disponível em: <https://goo.gl/QyKYFj>. Acesso em: 15 mar. 2021.

CARVALHO, S. M. G.; PIO, P. M. A categoria da práxis em Pedagogia do Oprimido: sentidos e implicações para a educação libertadora. Revista brasileira de estudos pedagógicos, Brasília, v. 98, n. 249, p. 428-445, maio/ago. 2017.

ESPINOSA, B. R. S; QUEIROZ, F. B. C. Breve análise sobre as redes do Escola sem Partido. In: FRIGOTTO, Gaudêncio (org.). Escola "sem" partido: esfinge que ameaça a educação e a sociedade brasileira. Rio de Janeiro: UERJ, 2017. p. 49-62.

FREIRE, P. Pedagogia do Oprimido. 69. ed. Rio de Janeiro/São Paulo: Paz e Terra, 2019.

FREIRE, P. Pedagogia da Esperança: um reencontro com a Pedagogia do Oprimido. 25. ed. Rio de Janeiro/São Paulo: Paz e Terra, 2019a.

FREIRE, P. Educação como prática da liberdade. 45. ed. São Paulo: Paz e Terra, 2019b.

FREIRE, P. Conscientização. 1. ed. São Paulo: Cortez, 2016.

FREIRE, P. Pedagogia da autonomia: saberes necessários à pratica educativa. 16. ed. São Paulo: Paz e Terra, 1996.

HERMIDA, J. F.; LIRA, J. S. Desconstruindo a lógica da Escola Sem Partido: glosas críticas. Revista Exitus, Santarém, v. 11, 2021, p. 01-25.

LEHER, R. Guerra Cultural e Universidade Pública: O Future-se é parte da estratégia de silenciamento. In: GIOLO, J. Future-se: ataque à autonomia das instituições federais de 
educação superior e sua sujeição ao mercado. São Carlos, SP: Diagrama Editorial, 2020. p. 107-152.

SAVIANI, D. As concepções pedagógicas na história da educação brasileira. Campinas, ago., 2005. Disponível em: <https://www.histedbr.fe.unicamp.br/pfhistedbr/dermeval_saviani_artigo.pdf >. Acesso em: 8 ago. 2020.

SCOCUGLIA, A. C. Pedagogia do oprimido (1968-2018): da revolução ao reencontro da esperança. Educação em perspectiva, Brasil, v. 9, n. 3, set./dez. 2018.

SGUISSARDI, V. Future-se: um projeto neoliberal de heteronomia das federais e um passo a mais rumo a sua privado-mercantilização. In: GIOLO, J. Future-se: ataque à autonomia das instituições federais de educação superior e sua sujeição ao mercado. São Carlos, SP: Diagrama Editorial, 2020. p. 153-193.

VASCONCELOS, V. O.; BRANDÃO, C. R. 50 anos da Pedagogia do Oprimido: reflexões sobre (re)existência no Brasil e na América Latina. Artes de Educar, Brasil, v. 4, n. 2, 2018.

João Paulo Guerreiro de Almeida: Doutorando em Educação pela Universidade Federal da Parába. Pedagogo e Mestre em Educação pela Universidade Estadual do Ceará. Professor do Instituto Federal de Educação, Ciência e Tecnologia do Ceará - IFCE campus Limoeiro do Norte.

Orcid: https://orcid.org/0000-0002-3055-8182

E-mail: joaopaulo.guerreiro@ifce.edu.br

Severino Bezerra da Silva: Doutor em Ciências Sociais pela Pontifícia Universidade Católica de São Paulo; Professor Titular da Universidade Federal da Parába, atuando no Programa de Pós-Graduação em Educação (PPGE), linha de pesquisa em Educação Popular e graduações de Pedagogia, História e Ciências Sociais.

Orcid: https://orcid.org/0000-0002-3062-6640

E-mail:severinobsilva@uol.com.br

Este periódico utiliza a licença Creative Commons Attribution 3.0, para periódicos de acesso aberto (Open Archives Initiative - OAI). 